4

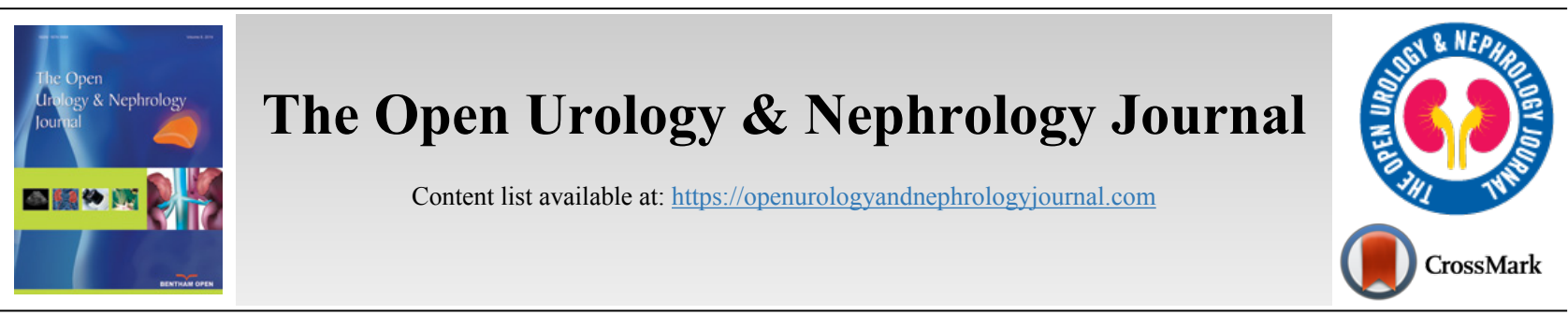

RESEARCH ARTICLE

\title{
Evaluation of Erectile Dysfunction in Nonobese, Nondiabetic Men with Obstructive Sleep Apnea
}

Ana Carolina D. Scoralick ${ }^{1, *}$, Alonço da C. Viana Júnior ${ }^{2}$, André L. Cavalcanti ${ }^{3}$, Ana Paula C. dos Santos ${ }^{1}$, Denise D. Neves $^{1}$ and Maria Helena A. Melo ${ }^{1}$

${ }^{1}$ Programme in Neurology, Federal University of the State of Rio de Janeiro, Rio de Janeiro, Brazil

${ }^{2}$ Department of Otolaryngology, Hospital Naval Marcilio Dias, Rio de Janeiro, Brazil

${ }^{3}$ Department of Urology, Federal University of the State of Rio de Janeiro, Rio de Janeiro, Brazil

\begin{abstract}
:
Background:

Erectile Dysfunction (ED) has affected people suffering from Obstructive Sleep Apnea Syndrome (OSAS) and multiple studies have confirmed this correlation.

Objective:

The objective of the is to identify the association between ED and Obstructive Sleep Apnea (OSA) in nonobese, nondiabetic men based on the International Index of Erectile Function (IIEF).

Methods:

This retrospective cross-sectional study included 143 nonobese, nondiabetic men with OSA (age, $\geq 20$ years) who visited the Sleep Outpatient Clinic of the Otorhinolaryngology Department at Hospital Naval Marcílio Dias from May 2017 to August 2018. Patient age, body mass index (BMI), drinking, smoking, laboratory diagnosis of hypogonadism based on total testosterone levels, and sleep parameters (e.g., apnea-hypopnea index, rapid eye movement density, and minimum Oxygen Saturation $\left[\mathrm{SatO}_{2}\right]$ ) were considered. Analysis of variance was used to evaluate means. The chi-squared test and Fisher's exact test were used to compare variables and Person's correlation coefficient was used to analyze numerical variables.

Results:

The mean minimum $\mathrm{SatO}_{2}$ was $78.89 \%$, and $46 \%$ of patients exhibited minimum $\mathrm{SatO}_{2}<80 \%$. Moreover, minimum $\mathrm{SatO}_{2}$ of $<80 \%$ and increasing age were associated with ED complaints based on IIEF scores,. A laboratory diagnosis of hypogonadism was associated with increased BMI, and aging was associated with $\mathrm{SatO}_{2}$

Conclusion:

The results of the study revealed that oxygen desaturation of $<80 \%$ was related to complaints of ED from the IIEF. Moreover, a relationship between laboratory hypogonadism and increased BMI values, aging, and oxygen desaturation has been demonstrated. Therefore, we recommend polysomnography in patients with ED complaints.
\end{abstract}

Keywords: Erectile dysfunction, Hypoxia, International index of erectile function, Obstructive sleep apnea, Polysomnography, Hypogonadism.

\begin{tabular}{|l|l|l|l|}
\hline Article History & Received: February 25, 2021 & Revised: May 17, 2021 & Accepted: June 28, 2021 \\
\hline
\end{tabular}

\section{INTRODUCTION}

Sleep quality is a fundamentally important factor to promote health and quality of life $[1,2]$. Over the years, evidence has demonstrated that sleep has a great impact on

\footnotetext{
* Address correspondence to this author at the Programme in Neurology, Federal University of the State of Rio de Janeiro, Rua Araguaia, 614, bloco 2/apartamento 503-Freguesia-Rio de Janeiro-RJ, Brazil; Tel: +5521997332607; Fax: +5521997332607; E-mail: anacarolinadaflon@gmail.com
}

people's physical and mental health [3]. In recent years, there has been a growing awareness of the important role of sex hormones in virtually all physiological processes, including breathing. Estrogen, progesterone, and testosterone can influence the respiratory function of humans and other animals $[4,5]$. Obstructive Sleep Apnea (OSA) is characterized by the intermittent collapse of the airway during sleep and is caused by hypotonia of the pharynx dilator muscles (including the genioglossus), resulting in hypoxemia, hypercarbia, and sleep 
fragmentation $[3,6]$. OSA is one of the most important conditions discovered in the last 50 years, given its high morbidity and mortality rates $[1,2]$. It is a highly prevalent sleep-related breathing disorder affecting $\sim 10 \%$ of men aged $30-49$ years, $17 \%$ of men aged $50-70$ years, $3 \%$ of women aged 30-49 years, and $9 \%$ of women aged $50-70$ years [7]. OSA is a serious and highly prevalent public-health problem, affecting $\sim 4 \%$ of men and $2 \%$ of women in the general population [8]. The leading risk factors for OSA are age, the male gender, obesity by Body Mass Index (BMI) criteria, and neck circumference [9 - 11]. Note that additional risk factors include East Asian ethnicity, structural abnormalities of the upper airways, alcohol abuse, and a family history of OSA [11]. All types of apnea become more prevalent with age, and central apneas increase even more with aging $[8,10]$. However, the severity of sleep apnea, assessed by the number of hourly events and minimum oxygen saturation $\left(\mathrm{SatO}_{2}\right)$, decreases with age, i.e., although its prevalence tends to increase with age, its clinical significance decreases [10]. The most common signs and symptoms of OSA are snoring, witnessed apnea episodes, and excessive daytime fatigue and somnolence. The secondary evaluation should include an investigation of systemic and pulmonary arterial hypertension and any history of stroke and Acute Myocardial Infarction (AMI) [11]. The consequences of OSA includeirritability, excessive daytime somnolence, lack of energy, headache, fatigue, reduced libido, respiratory changes, depression, heart disease, increased blood pressure, and other manifestations $[9,10]$. OSA is considered a complex disease that is usually associated with other conditions such as cardiovascular and cerebrovascular disease as well as endocrine disorders such as Erectile Dysfunction (ED) [12]. ED is defined as a consistent inability to have and/or maintain penile erection sufficient to allow effective sexual intercourse $[3,6]$. A study conducted in Turkey revealed an overall ED prevalence of $69.2 \%$ after adjustment for age. Moreover, the severity of ED increased with increasing age [13]. González et al. (2013) suggest that erectile dysfunction in sexually active patients may be classified into five categories according to erectile function: normal (26-30), mild (22-25), mild to moderate (17-21), moderate (11-16), and severe (1-10) [14]. Three large epidemiological studies on ED have been performed in Brazil. The first, conducted in 2000, was the study on the Sexual Behavior of Brazilians (ECOS), which had a sample of 2835 individuals at least 18 years old who lived in seven Brazilian cities. Of the 1332 men in that study, $46.2 \%$ had ED complaints [15]. The second, the study on the Sex Life of Brazilians (EVSB), was conducted during 2002 and 2003. It analyzed a sample of 2862 men aged over 40 years in which a $45.1 \%$ ED incidence was reported [16]. The last study, conducted in 2006, was called Populational Study of Aging (EPE). In it, 5751 men over 40 years old from 18 state capitals and from the national capital city, Brasília, were interviewed. The results showed that $43.6 \%$ of the sample had ED [17]. Therefore, based on these studies, it can be assumed that the prevalence of ED in men over 40 years of age is $\sim 50 \%[18$, 19]. Several studies revealed a high prevalence of ED among men with OSA [5, 20 - 22]. In a cohort of 1946 male patients with suspected OSA in Taiwan, OSA was confirmed as an independent risk factor for ED [23]. Although not lethal, ED causes significant impairment in the well-being and quality of life of men afflicted by it [24]. Moreover, it can be an indicator of underlying diseases such as systemic arterial hypertension, diabetes mellitus, cardiopathy, obesity, prostatic disease, and depression [25]. Smoking, excessive alcohol consumption, and age are other risk factors considered to be associated with ED [26]. Men with OSA may present ED owing to several reasons. One of these reasons is that during every rapid eye movement (REM) sleep cycle, men exhibit a Sleep-Related Erection (SRE), which is important for maintaining the structural and functional integrity of the penile erectile tissue [27, 28]. Viana et al. [29] observed decreased REM density and total testosterone levels in patients with OSA. In OSA, the intermittent episodes of hypoxia prevent the occurrence of SRE, thereby harming erectile physiology [20, 27]. Reductions in oxygen availability during sleep are associated with central inhibition of the hypothalamic-pituitary-gonadal axis, probably attributed to increased central endorphin levels [30]. The relative importance of hypoxia and sleep fragmentation in the onset of gonadal dysfunction was described in previous studies, which reported that sleep deprivation was associated with the suppression of gonadal steroid levels in healthy young adults [31 - 34]. Furthermore, when patients are exposed to repetitive episodes of upper airway obstruction with distinct sleep fragmentation, the circadian rhythm of testosterone may be affected [35]. When patients with OSA and $\mathrm{SatO}_{2}$ below $90 \%$ were studied, a significant correlation was found between peak testosterone levels and total desaturation time. This suggests that hypoxia was the factor responsible for the change in the circadian rhythm of testosterone by causing reduced morning levels of this hormone [34]. Patients with OSA who have chronic hypoxemia may have ventilation changes because hypoxemia affects the synthesis and activity of several neurotransmitters, thereby causing changes in the functioning of the central and peripheral chemoreceptors responsible for ventilation control [35]. Men who do not sleep well are three times more likely to have ED than those who sleep well. This epidemiological survey was conducted by Episono (2007) through questionnaires administered to 1042 volunteers in São Paulo. The results showed that a third of those volunteers had been diagnosed with sleep apnea. In that same survey, $17 \%$ of the men reported having ED; of these, 7\% were between 20 and 29 years old and $60 \%$ were 60 years or older. According to the study by Santos et al. sleep deprivation reduces testosterone levels [2]. This hormone is responsible for male characteristics such as sexual desire and the metabolization of fats. Patients with OSA frequently have ED. According to López-Jiménez et al. (2008), 20\% of the patients with ED have OSA, and 33\% of individuals with OSA have ED, reduced libido, or both [36]. Altered autonomic vascular control, endothelial dysfunction, and sleep fragmentation are possible mechanisms by which OSA predisposes an individual to ED [30]. The authors concluded that a high proportion $(45.9 \%)$ of Brazilian men over 40 years old have some degree of ED with the prevalence and severity of this condition increasing with age. Variables related to lifestyle and health status associated with ED may alert physicians about patients who are at risk for ED and provide clues about its etiology. Studies analyzing ED in individuals with OSA have demonstrated a high prevalence (25-27). A cohort of 1946 male patients in Taiwan confirmed OSA as an independent risk factor for ED [23]. A high 
prevalence had already been observed in previous studies, such as those by Guilleminault et al. [37], which showed ejaculatory dysfunction and reduced libido in $48 \%$ of male patients with OSA, as well as those by Hirshkowitz et al., who observed that $91.3 \%$ of patients with ED symptoms had OSA [27, 34]. However, some authors, such as Schiavi et al. (1991), do not confirm this finding [38]. In two studies conducted by Moreira et al. in Northeastern Brazil, the prevalence of ED in patients with OSA was estimated to be $39.5 \%$ and $40 \%$, respectively $[39,40]$. Molina et al., in a study conducted in the city of São Paulo, demonstrated a $50 \%$ prevalence of low total serum testosterone levels in men with OSA and a mean age of 44.6 years [3]. The studies by Kouchiyama et al. and Luboshitzky et al. demonstrated the influence of the Apnea-Hypopnea Index (AHI) on testosterone secretion and emphasized the degree of hypoxia [41, 42]. However, hypoxia and sleep fragmentation probably influence pituitary-gonadal function in patients with OSA. The significant association between decreased levels of testosterone and AHI suggests that gonadal dysfunction is a consequence of OSA rather than a primary change independent from the hypothalamus-pituitary-gonad axis [38]. The central nervous system controls respiratory functions from the nose down to the bronchioles, and it is an integral component of the respiratory regulation system and airway patency both in the waking state and during sleep. Serotonergic and noradrenergic neurons can constitute parallel pathways by directly stimulating the motor neurons of the hypoglossal nerve, which in turn regulate the muscles that dilate the upper airways. Thus, activation of these neurons increases the activity of the genioglossus muscle $[19,38]$. In a study with rats, Andersen et al. showed that REM sleep deprivation leads to reduced testosterone concentrations, a finding that confirms the importance of sleep homeostasis in endocrine regulation [43]. Other studies showed that reduced REM sleep density was reflected in a fragmented sleep pattern and was a risk factor for ED complaints [43]. Viana et al. conducted a study aimed at assessing the relationship between OSA and BMI [29]. These authors analyzed the records of 523 patients who had OSA diagnosed from 2013 to 2016 . The study included men with $\mathrm{BMI}<30 \mathrm{~kg} / \mathrm{m}^{2}$ and total testosterone (TT) levels measured in a blood sample collected in the morning after a sleep study. A total of 153 nonobese men met the inclusion criteria, and 47 of them (30.7\%) exhibited testosterone levels below the reference values; among these men, $44(93.6 \%)$ were overweight ( $p=$ 0.029). Decreased testosterone levels were significantly correlated with oxygen desaturation rates, the lowest $\mathrm{SatO}_{2}$ value $<80 \%$, and REM sleep duration, after adjusted for BMI. Only three patients with normal weight had reduced TT levels, all of them having minimum $\mathrm{SatO}_{2}<80 \%$ and aged over 50 years old. These authors concluded that in a large population of nonobese men with OSA there is an association between hypoxemia (minimum $\mathrm{SatO}_{2}<80 \%$ ), excess weight, and reduced testosterone levels. This association was observed only in individuals with normal weight and over 50 years old. The association of OSA with ED has been widely discussed; however, there is a lack of studies without confounding factors that influence ED in the studied cohort. Thus, we examined the association between ED complaints and OSA in nonobese, nondiabetic men.

\section{MATERIALS AND METHODS}

This retrospective, cross-sectional study included male patients diagnosed with OSA using polysomnography (PSG) at the Outpatient Sleep Clinic of the Otorhinolaryngology Department at Hospital Naval Marcílio Dias from May 2017 to August 2018. The inclusion criteria were as follows: $\mathrm{BMI}<30$ $\mathrm{kg} / \mathrm{m}^{2}$, age $>20$ years at the time of PSG, confirmed OSA diagnosis using PSG, early morning TT levels (245-1836 $\mathrm{ng} / \mathrm{dl}$ ), previously completed IIEF questionnaire, the absence of craniofacial dysmorphism or temporomandibular dysfunction, and visible genetic syndromes as investigated using specific tests and examinations. The exclusion criteria were as follows, absence of minimum saturation data, use of antihypertensive drugs that affect ED (angiotensin-converting enzyme inhibitors/angiotensin II receptor antagonists, beta-blockers, methyldopa, and calcium channel blockers), and previously diagnosed ED and diabetes mellitus. The study was approved by the institution's research ethics committee (\#51104215.0.0000.5256). All participants signed an informed consent form. This study does not disclose personally identifiable information of any of the participants in any form. Hence, consent for publication is not applicable in this case. All clinical investigations were conducted according to the Declaration of Helsinki principles. The following data were collected in a previous routine consultation at the institution's clinic for sleep disorders and entered into an electronic medical record: age (on the day when basal PSG was performed), presence of systemic arterial hypertension, smoking, alcohol consumption, laboratory tests for hypogonadism including TT levels, BMI, score in the International Index of Erectile Function (IIEF) questionnaire (answered by the patient), and PSG parameters (AHI, percentage of REM sleep, and minimum $\mathrm{SatO}_{2}$ ). PSG tests were conducted in different sleep laboratories and their reports were issued by different specialists, all accredited by the Brazilian Association of Sleep Medicine (ABMS) according to the AASM 2015 criteria. BMI was calculated based on the weight and height measured during the medical consultation. Smoking and alcohol consumption were recorded during the consultation as either present or absent. Quantitative TT measurement was performed using a sample of peripheral venous blood collected in the morning and the competitive immunoassay method (direct chemiluminescent technology) using Access testosterone calibrators (Beckman Coulter, Brea, CA, USA). AHI, minimum $\mathrm{SatO}_{2}$, and REM sleep density were measured based on the PSG records, using proprietary Captações software (EMSA Equipamentos Médicos, Rio de Janeiro, Brazil) for data acquisition and the PoliWin software (EMSA Equipamentos Médicos) for the analysis of the tests. The acquisition and analysis of the PSG tests were performed in accordance with the American Sleep Disorders Association guidelines. The following channels were recorded: electroencephalogram, electrocardiogram, bilateral electrooculogram, electromyogram, thoracic and abdominal respiratory inductance plethysmography belts, nasal airflow by thermistor, $\mathrm{SatO}_{2}$ using a peripheral oximeter, and the equivalent electric snoring signal. The IIEF questionnaire was given to the patients for self-administration. The patients were instructed on the objectives of the questionnaire and how it 
should be answered. The questionnaire consisted of multiplechoice questions with five statements for each question. The following data were collected during previous visits as part of routine procedures in the Outpatient Sleep Clinic and registered in electronic medical records: age (on the day of baseline PSG), systemic hypertension, smoking, drinking, laboratory diagnosis of hypogonadism based on TT levels, BMI, IIEF questionnaire score (completed by the patients themselves), and PSG parameters (Apnea-Hypopnea Index [AHI], percentage of REM sleep, and minimum Oxygen Saturation $\left.\left[\mathrm{SatO}_{2}\right]\right)$. PSG was performed at different sleep laboratories with reports by different specialists accredited by the Brazilian Sleep Society according to the criteria of the American Academy of Sleep Medicine [44, 45]. Trocar esse paragrafo pelo texto acima. Patients were categorized into the following age groups: young adults (age, 20-39 years), adults (age, $40-59$ years), and older adults (age, $\geq 60$ years). Regarding BMI, patients were grouped according to the World Health Organization classification as normal weight $\left(18.5-24.9 \mathrm{~kg} / \mathrm{m}^{2}\right)$ and overweight $\left(25.0-29.9 \mathrm{~kg} / \mathrm{m}^{2}\right)$. The laboratory diagnosis of hypogonadism was defined as TT levels of less than $245 \mathrm{ng} / \mathrm{dl}$ (normal levels, 245-1836 ng/dl) according to the hormone measuring system protocol of the hospital's central laboratory using direct chemiluminescence immunoassay with Access testosterone calibrators (Beckman Coulter, MN, USA). OSA was classified according to the AHI as mild (AHI = 5-14.9 events/h), moderate $(\mathrm{AHI}=15-29.9$ events $/ \mathrm{h})$, or severe $(\mathrm{AHI}$ $\geq 30$ events $/ h$ ). Apnea was identified when the airflow amplitude was flat or nearly flat for more than $10 \mathrm{~s}$, being classified as obstructive when respiratory effort persistence was detected via thoracoabdominal inductance plethysmography and classified as central in the absence of effort. Hypopnea was identified when the airflow amplitude was reduced by $30 \%$ for at least $10 \mathrm{~s}$ in conjunction with oxygen desaturation $\geq 3 \%$ or electroencephalogram arousal. Minimum $\mathrm{SatO}_{2}$ was classified as $\geq 90 \%$ and $<90 \%$ based on pulse oximetry [45]. We also considered minimum $\mathrm{SatO}_{2}=$ $80 \%$ as the cutoff based on a previous study by Viana et al. [29]. The REM density was considered normal at $20 \%-25 \%$ of total sleep time and decreased at $<20 \%$. ED was evaluated using the previously validated Portuguese version of the IIEF questionnaire comprising 15 questions grouped into five domains: erectile strength $(n=6)$, orgasm $(n=2)$, sexual desire $(n=2)$, satisfaction with intercourse $(n=3)$, and overall satisfaction $(n=2)$. Each question has a varying score, and the sum of the scores generates a final score that indicates whether the quality of sex life is normal (score $=22-25)$ or altered (score $<21$ ) [43]. Analysis of variance (ANOVA) was used to compare mean values. Factorial ANOVA was used to evaluate the factors that affected indices in combination. Inference by confidence intervals allowed us to visually confirm the means that were statistically different or equal. Tukey's test was used to identify statistical differences observed via ANOVA. Levene's test was used to analyze the assumption of homogeneity of variance [46]. The chi-squared test and Fisher's exact test were used for pairwise comparisons of the variables. The numerical variables of the study were analyzed using Pearson's correlation coefficient. The following software programs were used: STATISTICA 8.0 (STATSOFT, Palo
Alto, CA, USA) and SPSS 20.

\section{RESULTS}

The study sample comprised 143 men with a mean age of 46.52 years $(95 \%$ Confidence Interval $[\mathrm{CI}]=44-49)$. The mean BMI of the sample was $26.98 \mathrm{~kg} / \mathrm{m}^{2}(95 \% \mathrm{CI}=27-27)$, with no significant differences among the age groups (Fisher's $\mathrm{F}[2,140]=1.2885, p=0.278)$. There was a higher prevalence of overweight men in all age groups. The mean AHI in the sample was $26.42 / \mathrm{h}(95 \% \mathrm{CI}=23-30)$. When evaluated by age group, there was an increase in severity among men older than 40 years $(p=0.173)$. In addition, $45 \%$ of patients with OSA had ED complaints $(p=0.201)$. An analysis of OSA severity based on AHI revealed no significant association with ED complaints. In REM sleep analysis, we obtained a mean REM density of $17.93 \%(95 \% \mathrm{CI}=17-19)$ in the studied sample. No significant relationship was identified between ED complaints and reduced REM sleeps (Table 1). Concerning minimum $\mathrm{SatO}_{2}$, the mean value was $78.89 \%(95 \% \mathrm{CI}=76-80)$, and $90 \%$ of men exhibited depressed saturation $(<90 \%)$. ANOVA revealed a significant association between ED complaints and minimum $\mathrm{SatO}_{2}<80 \%(p=0.007)$ in the studied age groups (Fig. 1). There was no statistically significant association ( $p=$ 0.771 ) between minimum $\mathrm{SatO}_{2}<90 \%$ and $\mathrm{ED}$ complaints; however, using a minimum $\mathrm{SatO}_{2}$ cutoff of $80 \%$, we observed a significant association $(p=0.004)$, as demonstrated in Table $\mathbf{1}$. The mean TT level in the samples was $333.64 \mathrm{ng} / \mathrm{dl}$ (95\% CI = 314-362). Moreover, significant differences were observed between age groups and with regard to ED complaints (IIEF) (Table 2). On the contrary, AHI $(p=0.513), \operatorname{REM}$ density ( $p=$ $0.366)$, TT $(p=0.701)$, hypertension $(p=0.876)$, and smoking $(p=0.157)$ were not associated with ED complaints in different age groups. We were unable to analyze the association with drinking because of the small number of patients in some groups. The analysis of the numerical variables of the study (TT, age, BMI, IIEF, minimum $\mathrm{SatO}_{2}$, and REM density) using the Pearson coefficient revealed significant correlations, as shown in Fig. (1). As indicated in Fig. (2), no relationship was observed between ED, based on the IIEF score, and saturation in our young (age, 20-39 years) and middle-aged (age, 40-59 years) groups; however, in the elderly group (age, $\geq 60$ years), as saturation decreases, the ED rate increases $(\mathrm{p}<0.001)$.

\section{DISCUSSION}

In a study by Santos et al. [6], the frequency of ED among patients with OSA was $64.4 \%$, exceeding the value in the present study. Conversely, in a study by Zias et al. [32], only $20 \%$ of patients with ED experienced OSA. Santos et al. [6] reported that the risk of ED increases with aging. According to Stannek et al. [47], age has a greater impact on erectile function than OSA severity. This was also demonstrated in a study by Andersen et al. $[43,46]$ and confirmed in our study ( $p$ $=0.002$ ). Using AHI and minimum $\mathrm{SatO}_{2}$, OSA displayed no independent correlation with ED. Santos et al. [2] found no association between BMI and ED, and patients with BMI values of $25-29 \mathrm{~kg} / \mathrm{m}^{2}$ were more symptomatic than those with higher BMI. This may be explained by the fact that compared with the other categories, the overweight category included 
older patients ( $43 \%$ of patients aged $56-65$ years and $50 \%$ of patients older than 65 years) [6]. Aging was a confounding factor when analyzing BMI data. Even after excluding obese patients, our study uncovered inverse correlations of BMI and minimum $\mathrm{SatO}_{2}$ with TT levels; however, TT content was correlated with the severity of OSA. It is known that metabolic syndrome and obesity play a major role in the occurrence of urological diseases and OSAS. Sönmez et al. [48] showed that metabolic syndrome could negatively affect the effectiveness of alfuzosin therapy in the treatment of moderate urinary tract symptoms. To reduce the influences of obesity, in our article, we have excluded this group of patients from obtaining a study sample with fewer non-urological factors causing OSAS. Lima et al. [49] reported similar findings for BMI and OSA. In our study, there was no association between ED and AHI in different age groups, similar to the findings of Santos et al. [2]. However, Margel et al. observed that ED was exclusively associated with severe OSA [21]. A previous study by our group [32] revealed a correlation between TT levels and the REM density. The present study observed statistical significance for this correlation; however, when comparing ANOVA means, we were unable to establish a correlation between the REM density and IIEF. When comparing minimum $\mathrm{SatO}_{2}$ across age groups, we found the lowest levels of testosterone in individuals with the greatest total time of desaturation, which suggested that hypoxia was the factor responsible for the change of the circadian rhythm of testosterone, thereby causing a decrease in early morning testosterone levels. This was also demonstrated by our group in a previous study considering the cutoff point of minimum $\mathrm{SatO}_{2}$ of $80 \%$ in nonobese patients [32]. In the present study, when correlating minimum $\mathrm{SatO}_{2}$ with the degree of IIEF, we observed a statistically significant difference among individuals with minimum $\mathrm{SatO}_{2}$ levels lower than and higher than $80 \%$. However, when considering the minimum $\mathrm{SatO}_{2}$ cutoff of $90 \%$, no significant difference was observed in IIEF. We observed that the interaction factors age group and TT were not significantly associated with the IIEF score. We found no significant differences when comparing patients with normal and altered testosterone levels. Molina et al. [3] reported that serum testosterone levels decreased with advancing age and increasing weight. Harman et al. [50] observed that hypogonadal testosterone levels were $20 \%$ in men older than 60 years, $30 \%$ in men older than 70 years, and $50 \%$ in men older than 80 years. Moreover, we observed that laboratory diagnosis of hypogonadism was associated with decreased TT levels with aging, increased BMI, and oxygen desaturation, as also demonstrated by Luboshitzky et al. [34, $35,43]$. Similar to other studies on this topic, the present study had some limitations. The characteristics of the sample limited the number of analyzed variables because of the small number of participants, which may have hindered the identification of additional correlations. A larger sample would have allowed for the analysis of more clinical variables, albeit at the cost of additional confounding factors. Additional studies may corroborate our findings.

Table 1. Relationships of variables with the IIEF score.

\begin{tabular}{|c|c|c|c|}
\hline \multirow{2}{*}{ Variables } & \multicolumn{2}{|c|}{ IIEF } & \multirow{2}{*}{ p value } \\
\hline & Absent (22-25) & Present (21-5) & \\
\hline Age, years & 79 & 64 & \multirow{4}{*}{$<0.001$} \\
\hline $20-39$ & $39(49 \%)$ & $8(13 \%)$ & \\
\hline $40-59$ & $31(88 \%)$ & $34(66 \%)$ & \\
\hline$\geq \geq 60$ & $9(100 \%)$ & $22(100 \%)$ & \\
\hline \multicolumn{4}{|c|}{ BMIBMI, $\mathrm{kg} / \mathrm{m}^{2}$} \\
\hline $18.5-24.9$ & $22(28 \%)$ & $9(14 \%)$ & \multirow{2}{*}{0.07} \\
\hline$>24.9$ & $57(100 \%)$ & $55(100 \%)$ & \\
\hline \multicolumn{4}{|c|}{ Smoking } \\
\hline Smokers & 0 & $5(8 \%)$ & \multirow{3}{*}{0.08} \\
\hline Former smokers & $2(3 \%)$ & $4(14 \%)$ & \\
\hline Nonsmokers & $77(100 \%)$ & $55(100 \%)$ & \\
\hline \multicolumn{4}{|c|}{ Drinking } \\
\hline Absent & $79(100 \%)$ & $61(95 \%)$ & \multirow{2}{*}{0.31} \\
\hline Present & 0 & $3(100 \%)$ & \\
\hline \multicolumn{4}{|c|}{ SHTSHT } \\
\hline Present & $10(13 \%)$ & $21(33 \%)$ & \multirow{2}{*}{0.08} \\
\hline Absent & $69(100 \%)$ & $43(100 \%)$ & \\
\hline \multicolumn{4}{|c|}{ TTTT } \\
\hline Altered $(<245 \mathrm{ng} / \mathrm{dl})$ & $15(11 \%)$ & $22(34 \%)$ & \multirow{2}{*}{0.04} \\
\hline Normal (245-1836 ng/dl) & $64(100 \%)$ & $42(100 \%)$ & \\
\hline \multicolumn{4}{|c|}{ AHIAHI } \\
\hline Mild & $33(42 \%)$ & $15(23 \%)$ & \multirow{3}{*}{0.12} \\
\hline Moderate & $26(75 \%)$ & $23(59 \%)$ & \\
\hline Severe & $20(100 \%)$ & $26(100 \%)$ & \\
\hline \multicolumn{4}{|c|}{ REMREM } \\
\hline
\end{tabular}


(Table 1) contd.....

\begin{tabular}{|c|c|c|c|}
\hline \multirow{2}{*}{ Variables } & \multicolumn{2}{|c|}{ IIEF } & \multirow{2}{*}{ p value } \\
\hline & Absent (22-25) & Present (21-5) & \\
\hline Normal $(20 \%-25 \%)$ & $39(49 \%)$ & $26(41 \%)$ & \multirow{2}{*}{0.29} \\
\hline Reduced $(<20 \%)$ & $40(100 \%)$ & $38(100 \%)$ & \\
\hline \multicolumn{4}{|l|}{ Minimum SatO,$\%$} \\
\hline$\geq \geq 90$ & $9(11 \%)$ & $4(6 \%)$ & \multirow{2}{*}{0.26} \\
\hline$<90$ & $70(100 \%)$ & $60(100 \%)$ & \\
\hline$\geq \geq 80$ & $51(65 \%)$ & $26(41 \%)$ & \multirow{2}{*}{0.004} \\
\hline$<80$ & $28(100 \%)$ & $38(100 \%)$ & \\
\hline $\begin{array}{c}\text { BMI }=\text { Body Mass Index } \\
2 \mathrm{SHT}=\text { Systemic Hypertension } \\
3 \mathrm{TT}=\text { Total Testosterone } \\
\text { 4AHI = Apnea-Hypopnea Index (mild: } 5-14.9 / \mathrm{h} \text {; moderate: } 15-29.9 / \mathrm{h} \text {; severe: } \geq 30 / \mathrm{h}) \\
5 \mathrm{SatO}=\text { Oxygen Saturation } \\
6 \mathrm{REM}=\text { Rapid Eye Movement } \\
7 \mathrm{IIEF}=\text { International Index of Erectile Function }\end{array}$ & & & \\
\hline
\end{tabular}
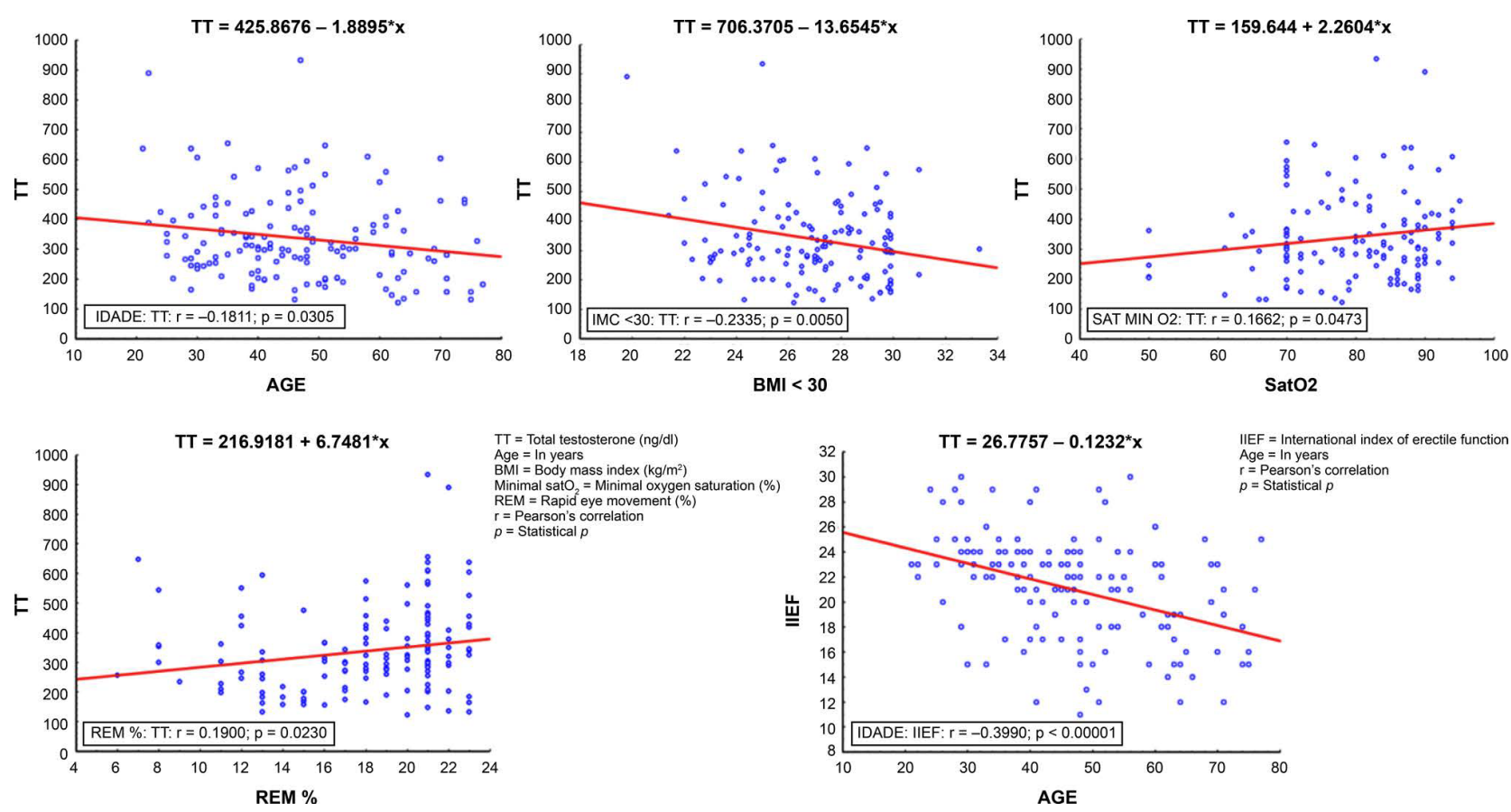

Fig. (1). Interaction between minimum oxygen saturation and age group in relation to the International Index of Erectile Function (IIEF) score.

Table 2. Comparison of erectile dysfunction complaints across age groups.

\begin{tabular}{|c|c|c|c|c|c|c|}
\hline \multirow{2}{*}{ Age Group (O) } & \multirow{2}{*}{ Age Group (Y) } & $\begin{array}{c}\text { Mean Difference } \\
(\mathbf{O}-\mathbf{Y})\end{array}$ & \multirow{2}{*}{ Standard Error } & \multirow{2}{*}{$\boldsymbol{p}$} & \multicolumn{2}{|c|}{$\mathbf{9 5 \%}$ CI } \\
\cline { 3 - 7 } & $20-39$ & $-4.46^{*}$ & 0.917 & $<0.001^{*}$ & -6.63 & -2.29 \\
\hline \multirow{2}{*}{$\geq 60$ years } & $40-59$ & -1.76 & 0.865 & 0.106 & -3.81 & 0.28 \\
\cline { 2 - 7 } & $\geq 60$ & $4.46^{*}$ & 0.917 & $<0.001^{*}$ & 2.29 & 6.63 \\
\cline { 2 - 7 } $20-39$ years & $40-59$ & $2.70^{*}$ & 0.758 & $0.002^{*}$ & 0.90 & 4.49 \\
\cline { 2 - 7 } & $\geq 60$ & 1.76 & 0.865 & 0.106 & -0.28 & 3.81 \\
\cline { 2 - 7 } & $20-39$ & $-2.70^{*}$ & 0.758 & $0.002^{*}$ & -4.49 & -0.90 \\
\hline
\end{tabular}

* Indicates Statistical Significance.

$\mathrm{CI}=$ Confidence Interval 


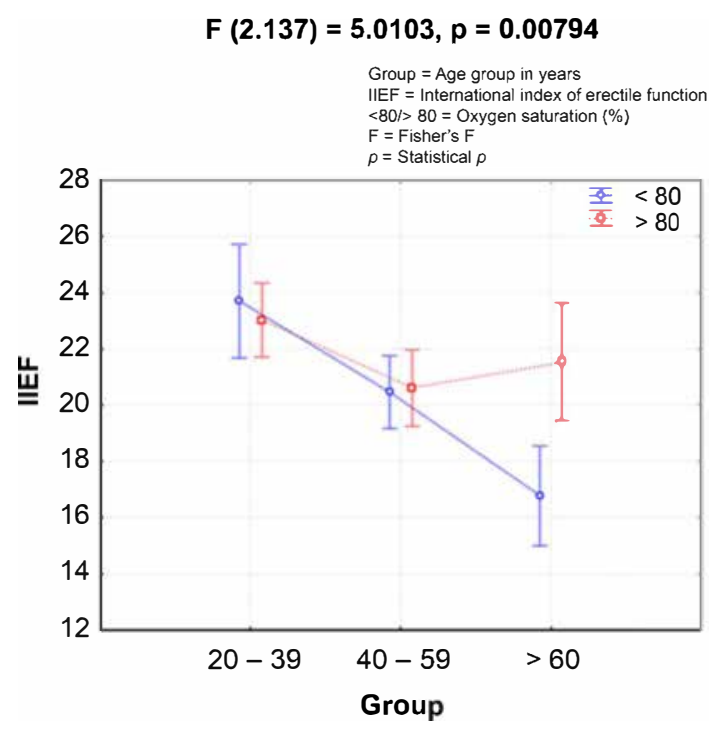

Fig. (2). Correlations of total testosterone levels with age, Body Mass Index (BMI), minimum oxygen saturation $\mathrm{SatO}_{2}$, and Rapid Eye Movement (REM) sleep as well as between the International Index of Erectile Function (IIEF) score

\section{CONCLUSION}

In conclusion, in a sample of nonobese, nondiabetic men with OSA, we found that oxygen desaturation of less than $80 \%$ was related to ED. We could not correlate ED with the laboratory diagnosis of hypogonadism. However, the laboratory diagnosis of hypogonadism correlated with increased BMI, older age, and oxygen desaturation.

\section{LIST OF ABBREVIATIONS}

$\begin{array}{ll}\begin{array}{l}\text { Brazilian } \\ \text { Association of Sleep } \\ \text { Medicine }\end{array} & \text { do Sono } \\ \text { AHI Apnea } & =\text { Hypopnea Index } \\ \text { AMI } & =\text { Acute Myocardial Infarction } \\ \text { BMI } & =\text { Body Mass Index } \\ \text { ED } & =\text { Erectile Dysfunction } \\ \text { IIEF } & =\text { International Index of Erectile Function } \\ \text { OSA } & =\text { Obstructive Sleep Apnea } \\ \text { PSG } & =\text { Polysomnography } \\ \text { REM } & =\text { Rapid Eye Movement } \\ \text { SatO } & =\text { Oxygen saturation } \\ \text { SRE } & =\text { Sleep-Related Erection } \\ \text { TT } & =\text { Total Testosterone }\end{array}$

\section{ETHICS APPROVAL AND CONSENT TO} PARTICIPATE

The study was approved by the institution's Research Ethics Committee (\#51104215.0.0000.5256).

\section{HUMAN AND ANIMAL RIGHTS}

No animals were used in this research. The acquisition and analysis of the PSG tests were performed in accordance with the American Sleep Disorders Association guidelines.

\section{CONSENT FOR PUBLICATION}

All participants signed an informed consent form. This study does not disclose personally identifiable information of any of the participants in any form.

\section{AVAILABILITY OF DATA AND MATERIALS}

The datasets generated during and/or analyzed during the current study are available from the corresponding author on reasonable request.

\section{FUNDING}

This research did not receive any specific grant from funding agencies in the public, commercial, or not-for-profit sectors.

\section{CONFLICT OF INTEREST}

The authors declare no conflict of interest, financial or otherwise.

\section{ACKNOWLEDGEMENTS}

Declared none.

\section{REFERENCES}

[1] Douglas N. Sleep apnea syndrome. Harrison's Principles of International Medicine. $17^{\text {th }}$ ed. Nueva York: McGraw-Hill 2008; Vol. 2: pp. 1665-8.

[2] Santos T, Drummond M, Botelho F. Erectile dysfunction in obstructive sleep apnea syndrome--prevalence and determinants. Rev Port Pneumol 2012; 18(2): 64-71.

[http://dx.doi.org/10.1016/j.rppneu.2011.10.004] [PMID: 22325836]

[3] Molina FD, Suman M, Carvalho TBO, et al. Evaluation of testosterone serum levels in patients with obstructive sleep apnea syndrome. Rev Bras Otorrinolaringol (Engl Ed) 2011; 77(1): 88-95. 
[http://dx.doi.org/10.1590/S1808-86942011000100015] [PMID: 21340195]

[4] Behan M, Wenninger JM. Sex steroidal hormones and respiratory control. Respir Physiol Neurobiol 2008; 164(1-2): 213-21. [http://dx.doi.org/10.1016/j.resp.2008.06.006] [PMID: 18599386]

[5] Sarris AB, Nakamura MC, Fernandes LGR, Staichak RL, Pupulim AF, Sobreiro BP. Pathophysiology, evaluation and treatment of erectile dysfunction: review article. Rev Med (São Paulo) 2016; 95(1): 18-29. [http://dx.doi.org/10.11606/issn.1679-9836.v95i1p18-29]

[6] Young T, Palta M, Dempsey J, Skatrud J, Weber S, Badr S. The occurrence of sleep-disordered breathing among middle-aged adults. $\mathrm{N}$ Engl J Med 1993; 328(17): 1230-5

[http://dx.doi.org/10.1056/NEJM199304293281704] [PMID: 8464434]

[7] Peppard PE, Young T, Barnet JH, Palta M, Hagen EW, Hla KM. Increased prevalence of sleep-disordered breathing in adults. Am J Epidemiol 2013; 177(9): 1006-14.

[http://dx.doi.org/10.1093/aje/kws342] [PMID: 23589584]

[8] Lorenzi Filho G. Apnéia obstrutiva do sono: um grave problema de saúde pública. Pneumologia Paulista: São Paulo 2008; 21(3): 5. [Obstructive sleep apnea: a serious public-health problem.].

[9] Mancini MC, Aloe F, Tavares S. Apnéia do sono em obesos. Sleep apnea in obese individuals. Arq Bras Endocrinol Metab São Paulo $81-90$.

[10] Neves GSML, Macedo P, Gomes MM. Transtornos do Sono: atualização. Rev Bras Neurol 2017; 53(3): 19-30.

[11] Guimarães GM. História clínica e exame físico em SAOS. J Bras Pneumol 2010; 36(Suppl. 2): S1-S61. [Clinical history and physical examination in OSA.].

[http://dx.doi.org/10.1590/S1806-37132010001400004]

[12] Duarte RLM, Silva RZM, Silveira FJM. Fisiopatologia da apnéia obstrutiva do sono. Pulmão RJ 2010; 19(3-4): 68-72.

[13] Akkus E, Kadioglu A, Esen A, et al. Prevalence and correlates of erectile dysfunction in Turkey: a population-based study. Eur Urol 2002; 41(3): 298-304.

[http://dx.doi.org/10.1016/S0302-2838(02)00027-1] [PMID: 12180232]

[14] González AI, Sties SW, Wittkopf PG, et al. Validação do Índice Internacional de Função Erétil (IIFE) para Uso no Brasil. Arq Bras Cardiol 2013; 101(2): 176-82. [Validation of the International Index of Erectile Function (IIEF) for use in Brazil.]. [PMID: 23842798]

[15] Abdo CHN. Perfil sexual da população brasileira: resultado do Estudo do Comportamento Sexual (ECOS) do Brasileiro. Rev Bras Med 2002; 59(4): 250-7. [Sexual profile of the Brazilian population: results of the Study on the Sexual Behavior of Brazilians (ECOS).].

[16] Abdo CHN, Oliveira WM Jr, Scanavino MdeT, Martins FG. Disfunção erétil: resultados do Estudo da Vida Sexual do Brasileiro. Rev Assoc Med Bras 2006; 52(6): 424-9. [Erectile dysfunction Results of the Study on the Sexual Life of Brazilians.] [http://dx.doi.org/10.1590/S0104-42302006000600023] [PMID: 17242780]

[17] Abdo CHN, Afif-Abdo J. Estudo populacional do envelhecimento (EPE): primeiros resultados masculinos. Rev Bras Med 2007; 64(8): 379-83.

[18] Riedner CE. Avaliação do efeito da obesidade na associação entre doença cardíaca isquêmica e disfunção erétil. Evaluation of the effects of obesity on the association between ischemic heart disease and erectile dysfunction 2010 .

[19] Jankowski JT, Seftel AD, Strohl KP. Erectile dysfunction and sleep related disorders. J Urol 2008; 179(3): 837-41.

[http://dx.doi.org/10.1016/j.juro.2007.10.024] [PMID: 18221960]

[20] Seftel AD, Strohl KP, Loye TL, Bayard D, Kress J, Netzer NC. Erectile dysfunction and symptoms of sleep disorders. Sleep 2002; 25(6): 643-7.

[http://dx.doi.org/10.1093/sleep/25.6.637] [PMID: 12227360]

[21] Margel D, Cohen M, Livne PM, Pillar G. Severe, but not mild, obstructive sleep apnea syndrome is associated with erectile dysfunction. Urology 2004; 63(3): 545-9.

[http://dx.doi.org/10.1016/j.urology.2003.10.016] [PMID: 15028455]

[22] Perimenis P, Konstantinopoulos A, Karkoulias K, Markou S, Perimeni P, Spyropoulos K. Sildenafil combined with continuous positive airway pressure for treatment of erectile dysfunction in men with obstructive sleep apnea. Int Urol Nephrol 2007; 39(2): 547-52. [http://dx.doi.org/10.1007/s11255-006-9079-4] [PMID: 17310311]

[23] Chen CM, Tsai MJ, Wei PJ, et al. Erectile dysfunction in patients with sleep apnea-A nationwide population based study. PLoS One 2015;
10(7): e0132510.

[http://dx.doi.org/10.1371/journal.pone.0132510] [PMID: 26177206]

[24] MacDonagh R, Ewings P, Porter T. The effect of erectile dysfunction on quality of life: psychometric testing of a new quality of life measure for patients with erectile dysfunction. J Urol 2002; 167(1): 212-7.

[http://dx.doi.org/10.1016/S0022-5347(05)65415-8] [PMID: 11743308]

[25] Harris M, Glozier N, Ratnavadivel R, Grunstein RR. Obstructive sleep apnea and depression. Sleep Med Rev 2009; 13(6): 437-44. [http://dx.doi.org/10.1016/j.smrv.2009.04.001] [PMID: 19596599]

[26] Somers VK, Dyken ME, Clary MP, Abboud FM. Sympathetic neural mechanisms in obstructive sleep apnea. J Clin Invest 1995; 96(4): 1897-904.

[http://dx.doi.org/10.1172/JCI118235] [PMID: 7560081]

[27] Hirshkowitz M, Schmidt MH. Sleep-related erections: clinical perspectives and neural mechanisms. Sleep Med Rev 2005; 9(4): 311-29.

[http://dx.doi.org/10.1016/j.smrv.2005.03.001] [PMID: 15994100]

[28] Moreland RB. Is there a role of hypoxemia in penile fibrosis: a viewpoint presented to the Society for the Study of Impotence. Int J Impot Res 1998; 10(2): 113-20.

[http://dx.doi.org/10.1038/sj.ijir.3900328] [PMID: 9647948]

[29] Viana A Jr, Daflon AC, Couto A, Neves D, de Araujo-Melo MH, Capasso R. Nocturnal hypoxemia is associated with low testosterone levels in overweight males and older men with normal weight. J Clin Sleep Med 2017; 13(12): 1395-401.

[http://dx.doi.org/10.5664/jcsm.6832] [PMID: 29065959]

[30] Singer F, Zumoff B. Subnormal serum testosterone levels in male internal medicine residents. Steroids 1992; 57(2): 86-9.

[http://dx.doi.org/10.1016/0039-128X(92)90035-8] [PMID: 1621262]

[31] Teloken PE, Smith EB, Lodowsky C, Freedom T, Mulhall JP. Defining association between sleep apnea syndrome and erectile dysfunction. Urology 2006; 67(5): 1033-7. [http://dx.doi.org/10.1016/j.urology.2005.11.040] [PMID: 16698364]

[32] Zias N, Bezwada V, Gilman S, Chroneou A. Obstructive sleep apnea and erectile dysfunction: still a neglected risk factor? Sleep Breath 2009; 13(1): 3-10.

[http://dx.doi.org/10.1007/s11325-008-0212-8] [PMID: 18766395]

[33] Behan M, Zabka AG, Thomas CF, Mitchell GS. Sex steroid hormones and the neural control of breathing. Respir Physiol Neurobiol 2003; 136(2-3): 249-63.

[http://dx.doi.org/10.1016/S1569-9048(03)00086-7]

[PMID: 12853015]

[34] Luboshitzky R, Lavie L, Shen-Orr Z, Herer P. Altered luteinizing hormone and testosterone secretion in middle-aged obese men with obstructive sleep apnea. Obes Res 2005; 13(4): 780-6.

[http://dx.doi.org/10.1038/oby.2005.88] [PMID: 15897488]

[35] Luboshitzky R, Zabari Z, Shen-Orr Z, Herer P, Lavie P. Disruption of the nocturnal testosterone rhythm by sleep fragmentation in normal men. J Clin Endocrinol Metab 2001; 86(3): 1134-9. [http://dx.doi.org/10.1210/jcem.86.3.7296] [PMID: 11238497]

[36] Martins AB, Tufik S, Moura SMGPT. Síndrome da apneia-hipopneia obstrutiva do sono. Fisiopatologia. J Bras Pneumol 2007; 33: 36-43. [http://dx.doi.org/10.1590/S1806-37132007000100017]

[37] Guilleminault C, Eldridge FL, Tilkian A, Simmons FB, Dement WC Sleep apnea syndrome due to upper airway obstruction: a review of 25 cases. Arch Intern Med 1977; 137(3): 296-300.

[http://dx.doi.org/10.1001/archinte.1977.03630150020008] [PMID: 557314]

[38] Schiavi RC, Mandeli J, Schreiner-Engel P, Chambers A. Aging, sleep disorders, and male sexual function. Biol Psychiatry 1991; 30(1): 15-24.

[http://dx.doi.org/10.1016/0006-3223(91)90066-U] [PMID: 1892958]

[39] Moreira JR, Lobo CFL, Glasser D. A population-based survey to determine the prevalence of erectile dysfunction and its correlates in the State of Bahia, Northeastern Brazil. J Urol 2000; 163(Suppl.): 15.

[40] Moreira ED Jr, Lisboa Lôbo CF, Villa M, Nicolosi A, Glasser DB. Prevalence and correlates of erectile dysfunction in Salvador, northeastern Brazil: a population-based study. Int J Impot Res 2002; 14(Suppl. 2): S3-9. [http://dx.doi.org/10.1038/sj.ijir.3900892] [PMID: 12161762]

[41] Kouchiyama S, Honda Y, Kuriyama T. Influence of nocturnal oxygen desaturation on circadian rhythm of testosterone secretion. Respiration 1990; 57(6): 359-63.

[http://dx.doi.org/10.1159/000195872] [PMID: 2099569]

[42] Luboshitzky R, Aviv A, Hefetz A, et al. Decreased pituitary-gonadal secretion in men with obstructive sleep apnea. J Clin Endocrinol 
Metab 2002; 87(7): 3394-8.

[http://dx.doi.org/10.1210/jcem.87.7.8663] [PMID: 12107256]

[43] Andersen ML, Bignotto M, Machado RB, Tufik S. Does paradoxical sleep deprivation and cocaine induce penile erection and ejaculation in old rats? Addict Biol 2002; 7(3): 285-90.

[http://dx.doi.org/10.1080/13556210220139497] [PMID: 12126487]

[44] American Academy of Sleep Medicine. International classification of sleep disorders: Diagnostic and coding manual. $2^{\text {nd }}$ ed. Westchester, IL: American Academy of Sleep Medicine 2012.

[45] Jelev A, Sood S, Liu H, Nolan P, Horner RL. Microdialysis perfusion of 5-HT into hypoglossal motor nucleus differentially modulates genioglossus activity across natural sleep-wake states in rats. J Physiol 2001; 532(Pt 2): 467-81.

[http://dx.doi.org/10.1111/j.1469-7793.2001.0467f.x] [PMID: 11306665]

[46] Andersen ML, Santos-Silva R, Bittencourt LRA, Tufik S. Prevalence of erectile dysfunction complaints associated with sleep disturbances in Sao Paulo, Brazil: a population-based survey. Sleep Med 2010; 11(10): 1019-24.

[http://dx.doi.org/10.1016/j.sleep.2009.08.016] [PMID: 20427234]
[47] Stannek T, Hürny C, Schoch OD, Bucher T, Münzer T. Factors affecting self-reported sexuality in men with obstructive sleep apnea syndrome. J Sex Med 2009; 6(12): 3415-24.

[http://dx.doi.org/10.1111/j.1743-6109.2009.01486.x] [PMID: 19751387]

[48] Sönmez G, Topaloglu US, Keske M, Demirtas A. Efficacy of alfuzosin in male patients with moderate lower urinary tract symptoms: Is metabolic syndrome a factor affecting the outcome? Urol J 2020; 17(5): 517-21.

[PMID: 32869259]

[49] Lima N, Cavaliere H, Knobel M, Halpern A, Medeiros-Neto G. Decreased androgen levels in massively obese men may be associated with impaired function of the gonadostat. Int $\mathbf{J}$ Obes Relat Metab Disord 2000; 24(11): 1433-7.

[http://dx.doi.org/10.1038/sj.ijo.0801406] [PMID: 11126339]

[50] Harman SM, Metter EJ, Tobin JD, Pearson J, Blackman MR. Baltimore longitudinal study of aging longitudinal effects on serum total and free testosterone levels in healthy men. J Clin Endocrinol Metab 2001; 86(2): 724-31.

[http://dx.doi.org/10.1210/jcem.86.2.7219] [PMID: 11158037]

\section{(c) 2021 Scoralick et al.}

This is an open access article distributed under the terms of the Creative Commons Attribution 4.0 International Public License (CC-BY 4.0), a copy of which is available at: https://creativecommons.org/licenses/by/4.0/legalcode. This license permits unrestricted use, distribution, and reproduction in any medium, provided the original author and source are credited. 